\title{
OPTIMIZATION OF EXTRACTION CONDITIONS OF VOLATILE COMPOUNDS OF ROASTED BEEF BY SOLID-PHASE MICROEXTRACTION
}

\author{
Vanessa C. Francisco $^{\mathrm{a}, *,(\mathbb{D}, \text { Larissa C. Almeida }}{ }^{\mathrm{b}}$, Stanislau Bogusz Junior ${ }^{\mathrm{b}}$, João Oiano Neto ${ }^{\mathrm{c}}$ and Renata T. Nassu $^{\mathrm{c}}$

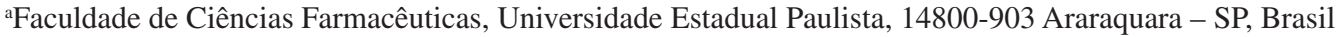 \\ 'Instituto de Química de São Carlos, Universidade de São Paulo, 13560-970 São Carlos - SP, Brasil \\ 'Embrapa Pecuária Sudeste, Rodovia Washington Luiz, km 234, 13560-970 São Carlos - SP, Brasil
}

Recebido em 01/11/2019; aceito em 18/01/2020; publicado na web em 31/03/2020

\begin{abstract}
Aroma is one of the most important sensory attributes for acceptance by beef consumers. The first step in analysing the volatile compounds associated with this attribute is their extraction from the food matrix, solid-phase microextraction has been widely used for volatile compound determination in meat. This study aimed to test six different solid-phase microextraction (SPME) fibre coating materials for their volatile compounds extraction efficiency for roasted beef and to optimize the extraction conditions using response surface methodology. Gas chromatography coupled with a flame ionization detector (GC-FID) and mass spectrometry (GC-MS) were used. The choice of SPME fibre coating was based in the total area obtained by GC-FID analysis for the six fibre coatings. The optimum time and temperature for SPME extraction was $60^{\circ} \mathrm{C} / 65$ minutes. The mixed-phase fibre coatings showed the best results for extracting volatile compounds in roasted beef as higher number of compounds were identified. The carboxen/polydimethylsiloxane (CAR/PDMS) fibre extracted the largest number of compounds under the optimum extraction condition. Aldehydes were the predominant class of compounds found in roasted beef, followed by alcohols and hydrocarbons.
\end{abstract}

Keywords: meat; aroma; gas chromatography-mass spectrometry.

\section{INTRODUCTION}

Aroma is one of the most important sensory attributes for the consumer acceptance of cooked beef. ${ }^{1}$ Raw beef shows a very mild aroma, a characteristic whey flavour and a lightly salty blood aroma. ${ }^{2}$ During cooking, various complex reactions occur, such as Maillard reactions, beta-oxidation of fatty acids and thiamine degradation. ${ }^{3}$ These reactions occur in non-volatile precursors, such as amino acids, peptides, reducing sugars, vitamins, nucleotides and fatty acids in beef, and contribute to the characteristic aroma of cooked beef. ${ }^{4}$

Headspace (HS) solid-phase microextraction (SPME) has been widely used for volatile compound determination in meat. ${ }^{5}$ Solid-phase microextraction is a simple and fast technique that combines analyte extraction and concentration, without the use of solvents and with a high sensitivity, to polar and non-polar compounds. ${ }^{6}$ The choice of SPME fibre-coating material is a key factor to achieve representative extraction of the cooked beef volatile compound profile. This selection must be done carefully because the concentration and type of volatile compounds that are extracted depend on the physico-chemical characteristics of the SPME fibre coating material. ${ }^{7}$ Among the commercially available materials, there are fibre coatings with polydimethylsiloxane (PDMS) indicated for non-polar compounds, polar materials such as polyacrylate (PA) for compounds with high polarity and mixed compounds such as polydimethylsiloxane/divinylbenzene (PDMS/DVB) and carboxen/ polydimethylsiloxane (CAR/PDMS) that can be used for volatile and non-volatile compounds from low to high polarity. ${ }^{8}$ For meat products, the mixed fibre coatings CAR/PDMS ${ }^{9,10}$ and DVB/CAR/ PDMS $^{11,12}$ are the most used.

Various studies have been published about the volatile compound profile in meat. ${ }^{11,13-15}$ Carboxen/polydimethylsiloxane and divinylbenzene/carboxen/polydimethylsiloxane were tested by Machiels and Istasse ${ }^{16}$ with various extraction times. In another study,

*e-mail: vanessacristina15@yahoo.com.br
DVB/CAR/PDMS was used to optimize the time and temperature of extraction. ${ }^{17}$ The mentioned studies used cooked beef, but there are no reports for roasted beef. In addition, there is a lack of studies reporting the optimization of extraction conditions by SPME using various compositions/polarities of fibre coatings to extract roasted beef volatile compounds. This study aimed to test six different SPME fibre coating materials for their volatile compounds extraction efficiency for roasted beef and to optimize the extraction conditions using response surface methodology.

\section{EXPERIMENTAL}

\section{Sample preparation}

A longissimus thoracis muscle obtained from a commercial abattoir was used in this study. Steaks of $2.5 \mathrm{~cm}$ thickness and approximately $50 \mathrm{~g}$ each were obtained, vacuum packed and kept frozen at $-18{ }^{\circ} \mathrm{C}$. For analysis, the samples were maintained at refrigeration temperature $\left(6^{\circ} \mathrm{C}\right)$ for 24 hours, and external fat was removed. Beef was roasted in an electric oven (NKS, Ford $9 \mathrm{~L}$, Rio de Janeiro, Brazil), which was previously pre-heated at $180{ }^{\circ} \mathrm{C}$ for 15 minutes, until the sample reached an internal temperature of $75^{\circ} \mathrm{C}$, as measured with an food thermometer (Alla France, 91000-050-F). After roasting, the sample was ground in a food processor (Walita, Viva RI1364/06, São Paulo, Brazil). Aliquots of $10 \mathrm{~g}$ of roasted beef were weighed in $60 \mathrm{~mL}$ flasks with screw top caps and PTFE/silicone septa. The sample preparation was the same for all steps of this study.

\section{Optimization of extraction conditions by SPME}

\section{Fibre coating material choice}

The six tested SPME fibre coatings were $75 \mu \mathrm{m}$ CAR/ PDMS (carboxen/polydimethylsiloxane), $65 \mu \mathrm{m}$ PDMS/DVB (polydimethylsiloxane/divinylbenzene), 50/30 $\mu \mathrm{m}$ DVB/CAR/PDMS (divinylbenzene/carboxen/polydimethylsiloxane), $100 \mu \mathrm{m}$ PDMS 
(polydimethylsiloxane), $70 \mu \mathrm{m} \mathrm{CAR} \mathrm{(carboxen)} \mathrm{and} 85 \mu \mathrm{m}$ PA (polyacrylate). All fibres were purchased from Supelco (Bellefonte, PA, USA). Before use, all fibres were conditioned according to the supplier's guidelines. To verify which fibre showed the best volatile compound extraction properties, the conditions were determined by preliminary tests and previous studies. ${ }^{18}$ The following conditions were used: extraction temperature $60{ }^{\circ} \mathrm{C}$, equilibrium time 10 minutes and extraction time 30 minutes. After extraction, the fibre was immediately inserted in the GC-MS injector. All six fibres were tested in triplicate, and the fibre with the best total area in the chromatogram was chosen for the next experiments to optimize the extraction conditions.

\section{Optimization of extraction conditions}

After the best fibre was chosen, the extraction conditions for the volatile compounds of roasted beef were optimized using the response surface methodology (RSM). A factorial central compound rotational design (CCRD) was used, with four axial points $(\alpha=1.4142)$ and three repetitions at the central point to a $2^{2}$ factorial design. ${ }^{19}$ The optimized variables were extraction time (minutes) and temperature extraction (Table 1). These variables were chosen, as they are reported to the those that most affect volatile compound extraction in meat by SPME. ${ }^{16,17}$ Eleven experiments were performed in a random order. Analysis was performed in a GC-FID as described following.

Table 1. Factors and levels for optimization of extraction conditions of beef volatile compounds by HS-SPME

\begin{tabular}{lccccc}
\hline \multirow{2}{*}{ Variables } & \multicolumn{2}{l}{ Coded Variables } & & \\
\cline { 2 - 6 } & $-\alpha^{\mathrm{a}}$ & -1 & 0 & 1 & $\alpha^{\mathrm{a}}$ \\
\hline Temperature $\left(\mathrm{T},{ }^{\circ} \mathrm{C}\right)$ & 20 & 26 & 40 & 54 & 60 \\
Time $(\mathrm{t}, \mathrm{min})$ & 10 & 26 & 65 & 104 & 120 \\
\hline
\end{tabular}

$\alpha=1.4142$.

Gas chromatography coupled with ion flame detector (GC-FID) analysis

For fibre choice and to optimize the extraction conditions, analyses were performed by gas chromatography with a GC-FID. After extraction, the SPME fibre was inserted directly in the injector of a gas chromatograph model GC-17A (Shimadzu, Kyoto, Japan) coupled to a Flame Ionization Detector (FID). The thermal desorption of the volatile compounds captured by the SPME fibre was performed at $250{ }^{\circ} \mathrm{C}$ in splitless mode for 1 minute. The fibre was kept inside the injector for 15 minutes for memory effect elimination. A fibre blank was run between each extraction procedure and injection to confirm that there was no memory effect. For chromatographic separation, a DB-5MS (5\% phenyl / 95\% dimethylpolysiloxane, $60 \mathrm{~m} \times 0.25 \mathrm{~mm}$ i.d. $\times 0.25 \mu \mathrm{m}$ of film thickness) fused silica capillary column from J\&W Scientific (Santa Clara, CA, USA) was used. The oven temperature program was: $70{ }^{\circ} \mathrm{C}$ for $2 \mathrm{~min}$, then increased to $180{ }^{\circ} \mathrm{C}$ at $4{ }^{\circ} \mathrm{C} \mathrm{min}^{-1}$ and finally raised to $300{ }^{\circ} \mathrm{C}$ at $60^{\circ} \mathrm{C} \mathrm{min}^{-1}$; it remained for $5 \mathrm{~min}$ at the final temperature. The detector temperature was $300^{\circ} \mathrm{C}$, and the carrier gas was nitrogen at a flow of $1.16 \mathrm{~mL} \mathrm{~min}^{-1}$.

\section{Separation and identification of volatile compounds by Gas Chromatography-Mass Spectrometry (GC-MS) at optimized condition}

Using the optimized time and temperature extraction conditions, roasted beef volatile compounds were identified using six different SPME fibre coatings to compare the extraction efficiency of each. These analyses were performed in a gas chromatograph, model
QP-2010 ULTRA (Shimadzu, Kyoto, Japan), coupled to a mass spectrometer with the same chromatographic conditions described for the GC-FID. The carrier gas was helium at a flow of $1 \mathrm{~mL} \mathrm{~min}^{-1}$, an electron ionization source at $+70 \mathrm{eV}$, and a simple quadrupole mass analyser monitoring the mass/charge range $(\mathrm{m} / \mathrm{z})$ from 35 to 350. A series of $n$-alkanes from $\mathrm{C}_{7}$ to $\mathrm{C}_{30}$ (Supelco, Bellefonte, PA, USA) was injected into the GC-MS with the samples under the same conditions to calculate the Linear Temperature Programmed Retention Index (LTPRI) for each compound. The compounds were tentatively identified by comparing the obtained LTPRI and the mass spectra of the samples to the literature (NIST, 2016), with a minimum similarity of $85 \%$ for the mass spectra and LTPRI maximum variation of \pm 10 .

\section{Statistical analysis}

The chromatographic area of six tested fibres was analysed by analysis of variance (ANOVA), and results were compared by Tukey test with 5\% significance. Data obtained from the central compound rotational design (CCRD) experiment were analysed by the Statistica v. 13 software (Statsoft Inc., Tulsa, OK, USA).

\section{RESULTS AND DISCUSSION}

\section{Fibre coating material choice}

The total area obtained by GC-FID analysis for the six tested fibre coatings is shown in Figure 1. Despite identical analytical conditions, as each fibre has a different coating material and consequently different polarity, the results show unique specific total areas in the chromatograms.

The choice of SPME fibre coating is based on the principle that "like dissolves like." In other words, non-polar compounds show a high affinity for non-polar phases such as PDMS; ${ }^{20}$ polar compounds show more affinity for polar phases such as CAR, and mixed fibres such as CAR/PDMS and DVB/CAR/PDMS are indicated for polar and non-polar volatile compounds. ${ }^{21}$

The mixed phase CAR/PDMS fibre showed a larger area $(\mathrm{P}<0.05)$ compared to the other phases tested, so it was chosen for the next step of this study. Similar results were found by Machiels and Istasse, ${ }^{16}$ who observed that the total areas of the compound peaks were larger when they were extracted with this fibre coating. Lorenzo ${ }^{7}$ also reported a higher extraction capacity of volatile compounds from dry horse meat with the same fibre coating.

\section{Optimization of extraction conditions}

The results from the experimental design with CAR/PDMS fibre coating shows that the quadratic time, quadratic temperature and linear temperature were significant, with a confidence interval of $95 \%$. All parameters were used for the experimental design to obtain the optimum temperature and time conditions for extraction. The experiments were performed at the central point $(n=3)$ aiming to estimate the pure error $(1.11 \mathrm{E}+11)$ and detect any lack of fit in the model.

The total area of the chromatograms is shown in Table 2. The chromatographic profiles for each experimental level tested in the CCRD experiment are shown in Figure 2. The distribution of the chromatograms in this figure follows the experimental design, with the minimum and maximum points of each parameter in the extremities and the axial points between them. Chromatogram B represents a central point repetition, and chromatogram I corresponds to experiment number 6 . An increase in the total peak area at $60{ }^{\circ} \mathrm{C}$ and at 65 minutes of extraction was observed. 


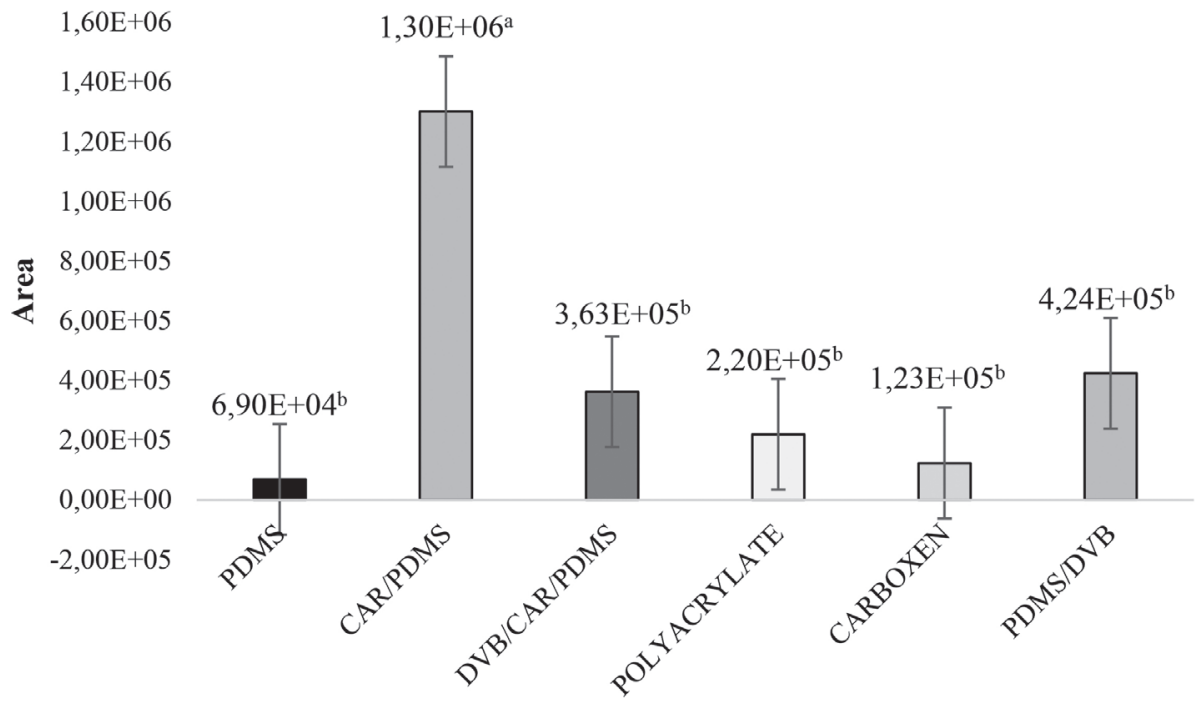

Fibres

Figure 1. Volatile compound extraction efficiency of SPME fibre coatings: PDMS - polydimethylsiloxane; CAR/PDMS - carboxen/polydimethylsiloxane; DVB/ $C A R / P D M S$ - divinylbenzene/ carboxen/ polydimethylsiloxane; PA - polyacrylate; CAR - carboxen; PDMS/DVB polydimethylsiloxane /divinylbenzene. The results are expressed as average values of triplicates of total areas. Extraction conditions: extraction temperature $60^{\circ} \mathrm{C}$; equilibrium time 10 minutes; extraction time 30 minutes

Table 2. Experimental conditions and total area obtained from CCRD for optimization of extraction conditions for roasted beef volatile compound extraction by HS-SPME

\begin{tabular}{cccccc}
\hline Experiment & Temperature $\left({ }^{\circ} \mathrm{C}\right)$ & Extraction temperature $\left({ }^{\circ} \mathrm{C}\right)$ & Time $(\mathrm{min})$ & Extraction time $(\mathrm{min})$ & Response $($ total area) \\
\hline 1 & -1 & 26 & -1 & 26 & 26 \\
2 & 1 & 54 & -1 & $1.53 \mathrm{E}+06$ & $2.67 \mathrm{E}+06$ \\
3 & -1 & 26 & 1 & 104 & $2.50 \mathrm{E}+06$ \\
4 & 1 & 54 & 1 & 65 & $2.86 \mathrm{E}+06$ \\
5 & -1.41 & 20 & 0 & 65 & $1.34 \mathrm{E}+06$ \\
6 & 1.41 & 60 & 0 & 10 & $6.86 \mathrm{E}+06$ \\
7 & 0 & 40 & 1.41 & 120 & $1.46 \mathrm{E}+06$ \\
8 & 0 & 40 & 0 & 65 & $1.11 \mathrm{E}+06$ \\
9 & 0 & 40 & 0 & 65 & $5.41 \mathrm{E}+06$ \\
11 & 0 & 40 & 0 & 65 & $5.54 \mathrm{E}+06$ \\
\end{tabular}

The HS-SPME technique is based on the equilibrium of the system's three phases: the food matrix, the headspace and the fibre coating material. ${ }^{22}$ Increased temperature can improve the extraction. ${ }^{20}$ In general, heating increases the vapour pressure of the compounds, improving the extraction process and facilitating the liberation of compounds into the headspace..$^{23}$

In the results from the ANOVA-calculated F statistical significance of the regression, which is the ratio between the regression means square and residue means square $\left(\mathrm{MQ}_{\mathrm{R}} / \mathrm{MQ}_{\mathrm{r}}\right)$, or calculated $\mathrm{F}$, is 7.04. When this value is compared to tabulated $\mathrm{F}$, at $95 \%$ significance (5.05), calculated $\mathrm{F}>$ tabulated $\mathrm{F}$, which means a correlation between the studied variable. The lack of fit of the model, given by the ratio between the quadratic mean of the lack of fit and the quadratic mean of the pure error, shows that the calculated $\mathrm{F}$ was lower than the tabulated F, indicating a good model fit that enables the model to be used at other temperatures and times of extraction. The relative standard deviation of $5.87 \%$ indicates adequate repeatability of the developed method under this condition.

The response surface graph obtained by CCRD is shown in
Figure 3. The optimum values for extraction temperature and time were $60{ }^{\circ} \mathrm{C}$ and 65 minutes. Although this optimum temperature and time combination can be considered long compared to those found in other studies for volatile compound extraction by SPME, the duration of 65 minutes is fairly reasonable if other methods such as Simultaneous Steam Distillation (SDE) or dynamic headspace using Tenax or Porapack Q traps..$^{23,18}$

\section{Identification of volatile compounds by GC-MS}

The volatile compounds of beef extracted using different fibre coating materials and identified by GC-MS in the optimized conditions are described in Table 3.

The selection of fibre coating type is determined by the physicochemical properties of the analytes, such as polarity, molecular mass and volatility. ${ }^{24}$ Depending on the SPME fibre coating, two processes can occur: adsorption or partition in fibres with a liquid stationary phase such as PDMS and PA or adsorption in polymeric fibres such as PDMS/DVB and CAR/PDMS, in which the extraction 

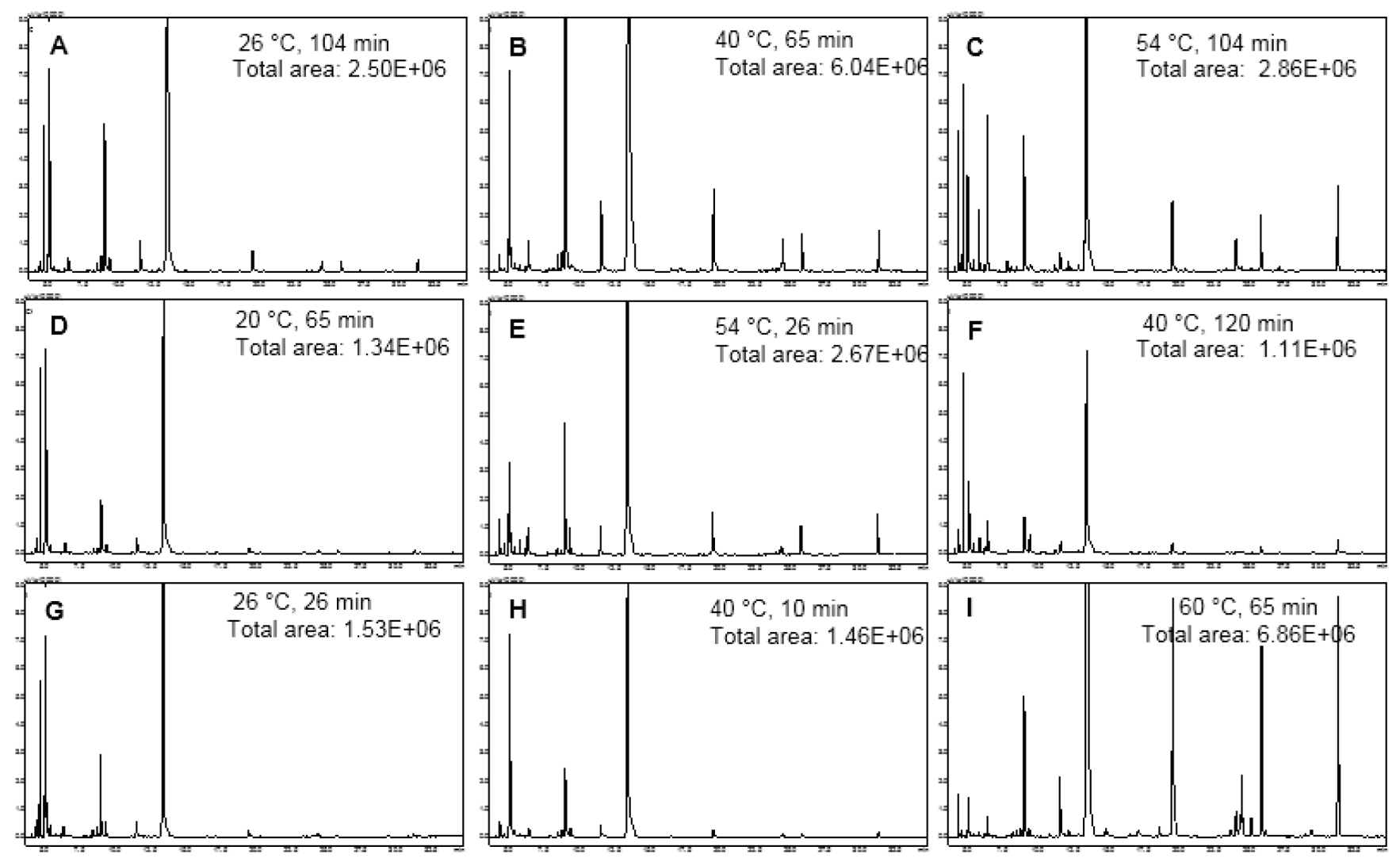

Figure 2. Chromatograms from CCRD experiment for optimization of extraction conditions of roasted beef volatile compounds by SPME using CAR/PDMS fibre coating

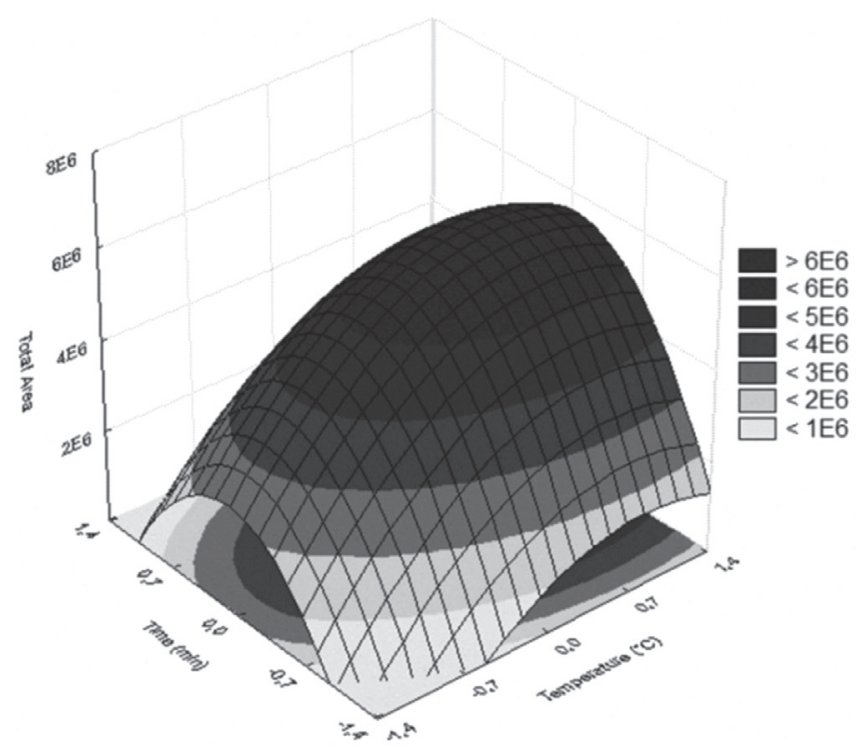

Figure 3. Response surface graph obtained by quadratic model: $y=5.66 E+06$ $+1.16 E+06 * T-8.59 E+05 * T^{\wedge} 2+8.36 E+04 * t-2.27 E+06 * t^{\wedge} 2-1.95 E+05 * T * t$, to optimize the time and temperature extraction conditions for roasted beef by HS-SPME

is due only to physical interactions. ${ }^{21}$ The PDMS fibre is indicated for apolar compound extraction, whereas PA fibre is used to extract polar compounds such as alcohols and phenols. Mixed-phase fibre coatings containing DVB or CAR increase the retention capacity due to a higher adsorption and distribution effect in the stationary phase and can be used for low molecular weight compounds. ${ }^{6}$

In this study, the mixed phase fibre coatings captured more compounds, and carboxylic acids, alkanes and esters were only observed when these fibre coatings were used. Some aldehydes, alcohols and aromatic compounds were extracted by all fibre types. The aromatic compounds 1-ethenyl-4-ethyl-benzene and 4-ethylbenzaldehyde were extracted only by the CAR fibre.

The fibre coating materials that extracted more volatile compounds was CAR/PDMS, followed by DVB/PDMS and DVB/CAR/PDMS (Table 3). Eight chemical classes were found among the 49 volatile compounds determined by the analysis: aldehydes (24.49\%), alcohols (20.4\%), hydrocarbons (16.33\%), sulphur compounds $(12.25 \%)$, aromatic compounds (12.25\%), ketones $(6.12 \%)$, carboxylic acids $(4.08 \%)$ and esters $(4.08 \%)$.

Previous studies with beef showed that mixed-phase fibre coatings were the most appropriate. Acevedo et al..$^{25}$ tested four fibre coatings (PDMS, PDMS/DVB, CAR/PDMS and DVB/CAR/PDMS) and two extraction temperatures $\left(40{ }^{\circ} \mathrm{C}\right.$ and $\left.50{ }^{\circ} \mathrm{C}\right)$ and observed that PDMS/ DVB and DVB/CAR/PDMS were the best. Machiels and Istasse ${ }^{16}$ evaluated CAR/PDMS and DVB/CAR/PDMS and concluded that the fibres affected the peak areas significantly and that higher total area values were obtained when the CAR/PDMS fibre was used.

Aldehydes and ketones result from Maillard reactions and Strecker degradation of carbohydrates and amino acids ${ }^{26}$ as well as lipid oxidation. ${ }^{27,28}$ Unsaturated and saturated aldehydes with 6 to 10 carbons are very important volatile compounds for beef aroma and are the main products from lipid degradation. ${ }^{14}$ Aldehydes are especially important for food aroma due to their low thresholds and contribute mainly "fatty" and "grass" notes. Aldehydes such as hexanal, octanal and nonanal were extracted by all six studied fibre coating materials. Hexanal is a product of linoleic acid oxidation, while octanal and nonanal are derived from oleic acid oxidation..$^{29}$ Other aldehydes, known as Strecker aldehydes, are formed during Maillard reactions and contribute to roasted beef aromas, such as 3-methylbutanal (toasted aroma) formed 
Table 3. Roasted beef volatile compounds by HS-SPME and GC-MS

\begin{tabular}{|c|c|c|c|c|c|c|c|c|c|c|}
\hline \multirow[b]{2}{*}{ RT } & \multirow[b]{2}{*}{ Compounds } & \multirow[b]{2}{*}{$\begin{array}{l}\text { LTPRI } \\
\text { (lit) }\end{array}$} & \multirow[b]{2}{*}{$\begin{array}{l}\text { LTPRI } \\
(\mathrm{cal})\end{array}$} & \multirow[b]{2}{*}{$\Delta$} & \multicolumn{6}{|c|}{ SPME fibre coating material } \\
\hline & & & & & $\begin{array}{l}\text { CAR } \\
\text { PDMS }\end{array}$ & $\begin{array}{l}\text { DVB } \\
\text { PDMS }\end{array}$ & $\begin{array}{c}\text { DVB } \\
\text { CAR } \\
\text { PDMS }\end{array}$ & PDMS & PA & CAR \\
\hline & Carboxylic acids & & & & & & & & & \\
\hline 14.4 & caproic acid & 1019 & 1014 & 5 & 7.61 & & & & & \\
\hline \multirow[t]{2}{*}{12.8} & 4-hidroxy-butanoic acid & 933 & 942 & -9 & 6.69 & & & & & \\
\hline & Hydrocarbons & & & & & & & & & \\
\hline 5.4 & 2,5-dimethylhexane & 758 & 766 & -8 & 5.48 & & & & & \\
\hline 5.9 & 2,2,5-trimethylhexane & 789 & 799 & -10 & 6.73 & & & & & \\
\hline 14.5 & 3-methylnonane & 976 & 969 & 7 & & & 5.43 & & & \\
\hline 16.3 & decane & 1000 & 1000 & 0 & 5.22 & 5.84 & 5.96 & & & \\
\hline 30.1 & dodecane & 1200 & 1200 & 0 & & 6.20 & 5.42 & & & \\
\hline 36.7 & tridecane & 1300 & 1300 & 0 & & & 5.86 & & & \\
\hline 34.4 & tetradecane & 1400 & 1400 & 0 & & 6.90 & & & & \\
\hline \multirow[t]{2}{*}{10.9} & nonane & 900 & 900 & 0 & & & 5.19 & & & \\
\hline & Alcohols & & & & & & & & & \\
\hline 5.5 & 1-pentanol & 779 & 780 & -1 & 5.79 & 4.71 & 5.76 & 4.84 & 5.93 & 5.02 \\
\hline 4.1 & 3-methyl-2-buten-1-ol & 785 & 784 & 1 & & & 4.99 & & & \\
\hline 6.7 & 2,3-butanediol & 819 & 816 & 3 & & & & & & 5.44 \\
\hline 9.0 & 1-hexanol & 869 & 870 & -1 & 5.12 & 5.10 & 5.39 & 4.28 & 5.33 & \\
\hline 15.5 & 1-heptanol & 984 & 989 & -5 & 6.87 & 5.44 & 6.63 & 4.44 & 5.53 & \\
\hline 16.1 & 1-octen-3-ol & 978 & 980 & -2 & 7.14 & 6.10 & 7.25 & 5.00 & 6.14 & \\
\hline 19.5 & 2-ethyl-1-hexanol & 1045 & 1047 & -2 & 6.35 & 7.70 & & & & \\
\hline 19.8 & 2-octen-1-ol & 1064 & 1070 & -6 & 6.30 & 4.93 & & & & \\
\hline 22.3 & 1-octanol & 1074 & 1074 & 0 & 5.47 & 6.45 & 7.10 & 4.78 & 6.07 & 5.75 \\
\hline \multirow[t]{2}{*}{28.2} & 1-nonanol & 1172 & 1174 & -2 & & & 5.88 & & & \\
\hline & Aldehydes & & & & & & & & & \\
\hline 2.6 & 3-methylbutanal & 736 & 736 & 0 & 6.56 & 4.67 & 5.61 & & & \\
\hline 3.2 & 2-methylbutanal & 739 & 739 & 0 & 4.62 & 4.96 & 6.20 & & & \\
\hline 5.9 & hexanal & 801 & 802 & -1 & 6.59 & 5.96 & 6.04 & 4.84 & 5.05 & 4.97 \\
\hline 11.2 & heptanal & 902 & 903 & -1 & 5.92 & 5.71 & 6.10 & 4.48 & 6.10 & 4.97 \\
\hline 16.6 & octanal & 1004 & 1003 & 1 & 6.17 & 7.18 & 6.03 & 5.70 & 6.31 & 5.70 \\
\hline 18.9 & 2-octenal & 1064 & 1074 & -10 & 6.26 & 5.02 & 6.95 & & & \\
\hline 24.5 & nonanal & 1108 & 1105 & 3 & 6.18 & 5.90 & 8.27 & 5.31 & 6.83 & 6.47 \\
\hline 27.3 & 2-nonenal & 1162 & 1160 & 2 & & 5.45 & 6.26 & & & \\
\hline 31.6 & decanal & 1207 & 1206 & 1 & 5.56 & 7.08 & 6.85 & 5.50 & 5.51 & 6.85 \\
\hline 36.9 & undecanal & 1311 & 1317 & -6 & & 6.39 & 6.18 & & & 6.33 \\
\hline 37.9 & 2-undecanal & 1376 & 1377 & -1 & & 5.71 & & & & \\
\hline \multirow[t]{2}{*}{38.5} & dodecanal & 1409 & 1406 & 3 & & 7.09 & & & & \\
\hline & Ketones & & & & & & & & & \\
\hline 5.8 & 3-hydroxy-2-butanone & 743 & 746 & -3 & 3.42 & 4.42 & 6.20 & & & 5.93 \\
\hline 5.7 & cyclopentanone & 797 & 796 & 1 & & & & & 5.01 & \\
\hline \multirow[t]{2}{*}{10.7} & 2-heptanone & 905 & 908 & -3 & 6.95 & & & & & \\
\hline & Sulphur compounds & & & & & & & & & \\
\hline 4.4 & dimethyl disulfide & 776 & 776 & 0 & 6.63 & 4.94 & 5.49 & 4.75 & & \\
\hline 9.4 & 2-ethylthiophene & 880 & 879 & 1 & 6.21 & & 4.95 & & & \\
\hline 10.7 & methional & 908 & 908 & 0 & & 4.86 & & & & \\
\hline
\end{tabular}


Table 3. Roasted beef volatile compounds by HS-SPME and GC-MS (cont.)

\begin{tabular}{|c|c|c|c|c|c|c|c|c|c|c|}
\hline \multirow[b]{2}{*}{ RT } & \multirow[b]{2}{*}{ Compounds } & \multirow[b]{2}{*}{$\begin{array}{c}\text { LTPRI } \\
\text { (lit) }\end{array}$} & \multirow[b]{2}{*}{$\begin{array}{c}\text { LTPRI } \\
\text { (cal) }\end{array}$} & \multirow[b]{2}{*}{$\Delta$} & \multicolumn{6}{|c|}{ SPME fibre coating material } \\
\hline & & & & & $\begin{array}{c}\text { CAR } \\
\text { PDMS }\end{array}$ & $\begin{array}{c}\text { DVB } \\
\text { PDMS }\end{array}$ & $\begin{array}{c}\text { DVB } \\
\text { CAR } \\
\text { PDMS }\end{array}$ & PDMS & PA & CAR \\
\hline 15.1 & dimethyl trisulfide & 981 & 981 & 0 & 6.14 & & & 5.51 & & \\
\hline 21.3 & 2-butylthiophene & 1072 & 1073 & -1 & 5.96 & & & & & \\
\hline \multirow[t]{2}{*}{25.4} & 5-methyl-2-thiophenecarboxaldehyde & 1135 & 1133 & 2 & 6.01 & & & & & \\
\hline & Aromatic compounds & & & & & & & & & \\
\hline 5.4 & toluene & 784 & 789 & -5 & 5.87 & 5.07 & 6.45 & & & \\
\hline 14.6 & benzaldehyde & 970 & 973 & -3 & 5.41 & 6.18 & 6.59 & 4.71 & 6.01 & 5.83 \\
\hline 15.8 & 2-pentylfuran & 996 & 991 & 5 & 7.24 & 6.06 & 7.04 & 4.84 & 5.30 & 6.18 \\
\hline 19.2 & benzeneacetaldehyde & 1043 & 1042 & 1 & & 5.22 & & & & \\
\hline 22.5 & 1-ethenyl-4-ethylbenzene & 1073 & 1083 & -10 & & & & & & 6.22 \\
\hline \multirow[t]{2}{*}{27.3} & 4-ethylbenzaldehyde & 1168 & 1160 & 8 & & & & & & 5.96 \\
\hline & Esters & & & & & & & & & \\
\hline 12.9 & $n$-hexylmethanoate & 947 & 943 & 4 & 5.78 & & & & & \\
\hline \multirow[t]{2}{*}{25.2} & octylmethanoate & 1128 & 1131 & -3 & & 5.62 & & & & \\
\hline & Identified compounds & & & & 31 & 30 & 28 & 14 & 13 & 14 \\
\hline
\end{tabular}

$\mathrm{RT}=$ retention time in minutes; LTPRI Calc. = Calculated Retention Index obtained using 5\% phenyl/95\% dimethylpolysiloxane capillary column; L-PRI Lit. = Literature Retention Index obtained using 5\% phenyl/95\% dimethylpolysiloxane capillary column; $\Delta=$ difference between calculated retention indices (LTPRI calc) and literature retention indices (LTPRI Lit $_{\text {. }}$.x means that the volatile compound was detected when the fibre was used. Peak area of compounds transformed in $\log 10$.

from the amino acid leucine and 2-methylbutanal (nutty aroma), which comes from the amino acid isoleucine. ${ }^{27}$ Some aldehydes are reduced, forming the corresponding alcohol. ${ }^{26}$ Linear chain alcohols with 5 to 9 carbons were found in this study: 1-pentanol (pungent aroma), extracted by the six tested fibres; 1-octen-3-ol (mushroom notes) and 1-hexanol (resinous and toasted aromas), which was not only extracted by the carboxen fibre. These alcohols are formed by linolenic acid degradation. ${ }^{30}$ Two esters were found: $n$-hexylmethanoate (related to fruit and sweet notes from banana and apple) and the octylmethanoate (fruity aroma). Esters are formed from the esterification of alcohols and acids. ${ }^{27}$ Ketones are obtained by the Maillard reaction and by lipid oxidation. In this study, 2-heptanone, which is related to fruity, spicy and cinnamon odours, ${ }^{31}$ was identified only by the CAR/PDMS fibre coating material. The 3-hydroxy 2-butanone (buttery aroma) was extracted per three mixed-phase fibres, and cyclopentanone (peppermint notes) was only identified with the polyacrylate fibre coating.

Lipid oxidation can generate hydrocarbons, alcohols, lactones, acids, benzenoids and benzaldehydes. ${ }^{27,28}$ In the studied samples, benzaldehydes (almond aroma, burning aromatic taste), benzene acetaldehyde (fatty, sweet and gamy notes) and 4-ethyl-benzaldehyde (bitter almonds sweet anis) were found.

Sulfur compounds such as dimethyl disulfide (onion and cabbage aroma), 2-ethylthiophene (grassy) and methional (cooked potato) can form during the Maillard reaction as intermediate products in the Strecker degradation and during cysteine and methionine degradation. Even in low concentrations, these compounds contribute to the composition of the grilled beef aroma. ${ }^{4}$ The thermal degradation of thiamine (B1 vitamin) originates many compounds that contain sulfur, obtained from the fragmentation and reorganization of thiazole rings. ${ }^{32}$ Methional is a product of this reaction, originating from methanethiol, which oxidizes easily to dimethyl sulfide (cabbage and sulfur notes) and dimethyl trisulfide (sulfurous aroma). ${ }^{26}$

\section{CONCLUSION}

For the numerous identified compounds, mixed-phase fibre coating materials showed the best results, and CAR/PDMS extracted the most compounds, in the optimized extraction temperature and time, $60{ }^{\circ} \mathrm{C}$ for 65 minutes, conditions established in this study. Aldehydes were the predominant class of compounds found in roasted beef, followed by alcohols and hydrocarbons.

\section{ACKNOWLEDGEMENTS}

The authors acknowledge financial support from Conselho Nacional de Desenvolvimento Científico e Tecnológico (CNPq) 472344/2012-9 and 134462/2014-9 for the project funding and M.Sc. scholarship respectively. This study was financed in part by the Coordenação de Aperfeiçoamento de Pessoal de Nível Superior - Brasil (CAPES) - Finance Code 001.

\section{REFERENCES}

1. Shahidi, F.; Flavor of meat and meat products, Springer: Boston, 1994, cap 1.

2. Ordóñez, J. A.; Tecnologia de Alimentos: Alimentos de Origem Animal - Volume 2, Artmed: Porto Alegre, 2005, cap. 8.

3. Elmore J. S.; Mottram, D. S.; Dodson, A. T. In Handbook of flavor characterization; Deibler, K. D., Delwiche, J., eds.; Marcel Dekker, New York, 2004, cap. 21.

4. Mottram, D. S.; Food Chem. 1998, 62, 415.

5. Watanabe, A.; Ueda, Y.; Higuchi, M.; Shiba, N.; Food Sci. 2008, 73, 420.

6. Kataoka, H.; Lord, H. L.; Pawliszyn, J.; J. Chromatogr. A 2000, 880, 35.

7. Lorenzo, J. M.; Meat Sci. 2014, 96, 179.

8. Pires Valente, A. L.; Augusto, F.; Quim. Nova 2000, 23, 523.

9. Saraiva, C.; Oliveira, I.; Silva, J. A.; Martins, C.; Ventanas, J.; García, C.; J. Food Sci. Technol. 2015, 52, 3887. 
10. Legako, J. F.; Brooks, J. C.; O’Quinn, T. G.; Hagan, T. D. J.; Polkinghorne, R.; Farmer, L. J.; Miller, M. F.; Meat Sci. 2015, 100, 291.

11. Vasta, V.; Luciano, G.; Dimauro, C.; Röhrle, F.; Priolo, A.; Monahan, F. J.; Moloney, A. P.; Meat Sci. 2011, 87, 282.

12. Dominguez, R.; Gomez, M.; Fonseca, S.; Lorenzo, J. M.; Meat Sci. 2014, 97, 223 .

13. Elmore, J. S.; Mottram, D. S.; Hierro, E.; J. Chromatogr. A 2001, 905 , 233.

14. Wettasinghe, M.; Vasanthan, T.; Temelli, F.; Swallow, K.; Food Res. Int. 2001, 34, 149 .

15. Watanabe, A.; Kamada, G.; Imanari, M.; Shiba, N.; Yonai, M.; Muramoto, T.; Meat Sci. 2015, 107, 12.

16. Machiels, D.; Istasse, L.; Talanta 2003, 61, 529.

17. Ma, Q. L.; Hamid, N.; Bekhit, A. E. D.; Robertson, J.; Law, T. F.; Microchem. J. 2013, 111, 16.

18. Madruga, M. S.; Elmore, S. J.; Dodson, A. T.; Mottram, D. S.; Food Chem. 2009, 115, 1081.

19. Ferreira, S. L. C.; Bruns, R. E.; da Silva, E. G. P.; dos Santos, W. N. L.; Quintella, C. M.; David, J. M.; de Andrade, J. B.; Breitkreitz, M. C.; Jardim, I. C.; Barros Neto, B.; J. Chromatogr. A 2007, 1158, 2.
20. Theodoridis, G.; Koster, E. H.; de Jong, G.; J. Chromatogr. B 2000, 745 , 49.

21. Parreira, F. V.; De Lourdes Cardeal, Z.; Quim. Nova 2005, 28, 646.

22. Steffen, A.; Pawliszyn, J.; J. Agric. Food Chem. 1996, 44, 2187.

23. Zhang, Z.; Pawliszyn, J.; Anal. Chem. 1993, 65,1843.

24. Queiroz, M. E. C.; Sci. Chromatogr. 2009, 1, 11.

25. Acevedo, C. A.; Creixell, W.; Pavez-Barra, C.; Sánchez, E.; Albornoz, F.; Young, M. E.; Food Bioprocess Technol. 2012, 5, 2557.

26. Belitz, H. D.; Grosch, W.; Schieberle, P.; Food Chemistry, Springer: Berlin Heidelberg, 2009.

27. Macleod, G. In Flavor of Meat and Meat Products; Shahidi, F., ed.; Springer: Boston, 1994, cap. 2.

28. Resconi, V. C.; Escudero, A.; Campo, M. M.; Molecules 2013, 18, 6748.

29. Ordonez, J. A.; Hierro, E. M.; Bruna, J. M.; de la Hoz, L.; Crit. Rev. Food Sci. Nutr. 1999, 39, 329.

30. Elmore, J. S.; Warren, H. E.; Mottram, D. S.; Scollan, N. D.; Enser, M.; Richardson, R. I.; Wood, J. D.; Meat Sci. 2004, 68, 27.

31. Calkins, C. R.; Hodgen, J. M.; Meat Sci. 2007, 77, 63.

32. Damodaran, S.; Parkin, K.; Fennema, O.; Química de Alimentos de Fennema, 4a ed., Artmed Editora: São Paulo, 2010. 